\title{
Associations of history of vaccination and hospitalization due to infection with risk of monoclonal B-cell lymphocytosis
}

Nicholas J. Boddicker ${ }^{1}$, Sara J. Achenbach ${ }^{2}$, Sameer A. Parikh ${ }^{3}{ }^{3}$, Geffen Kleinstern ${ }^{1,4}$, Esteban Braggio ${ }^{5}$, Aaron D. Norman ${ }^{6}$, Kari G. Rabe $\mathbb{D}^{2}$, Celine M. Vachon $\mathbb{D}^{6}{ }^{6}$, Connie E. Lesnick ${ }^{3}$, Timothy G. Call ${ }^{3}$, Janet E. Olson $\mathbb{D}^{6}{ }^{6}$, James R. Cerhan (iD) ${ }^{6}$, Neil E. Kay (D) ${ }^{3}$, Curtis A. Hanson ${ }^{7}$, Tait D. Shanafelt ${ }^{8}$ and Susan L. Slager (iD ${ }^{1,3 凶}$

(c) The Author(s) 2022

Leukemia (2022) 36:1404-1407; https://doi.org/10.1038/s41375-022-01514-3

\section{TO THE EDITOR}

Monoclonal B-cell lymphocytosis (MBL) is an asymptomatic condition defined by the presence of circulating clonal B-cells in peripheral blood with a similar immunophenotype to that of chronic lymphocytic leukemia (CLL) without clinical symptoms or signs of disease [1]. MBL is a precursor to $\operatorname{CLL}[2,3]$ and has been shown to be associated with risk of developing serious infection independent of progression to $\operatorname{CLL}[4,5]$.

Prior studies have suggested that common infections (e.g., pneumonia, herpes zoster, sinusitis) are associated with subsequent increased risk of CLL $[6,7]$. These studies infer that CLL patients may have a disturbed immune function prior to CLL diagnosis making the individuals more susceptible to infections. Infections may also have a role in the development of CLL, possibly through antigenic stimulation $[8,9]$. Interestingly, individuals with $\mathrm{MBL}$ also have an increased risk of subsequent infections [4,5], and some studies have suggested the clonal B-cell population may directly alter immune function [10]. Thus, it is currently unknown whether infection prior to developing CLL is due to infections being an inciting event to CLL, or if infections are strictly a consequence of having MBL.

Little is known about the history of infections and risk of developing MBL. In a study of 72 individuals with MBL and 380 controls, Casabonne et. al. reported increased risk of $\mathrm{MBL}$ in individuals with a history of pneumonia [11]. This study also reported that prior pneumococcal and influenza vaccinations were associated with reduced risk of MBL [11]. Moreover, two prior studies reported that select vaccinations may reduce risk of CLL $[12,13]$.

Here we evaluated prior history of serious infections and prior history of vaccinations with risk of $\mathrm{MBL}$ in a screening cohort of 1009 MBLs and 4419 known not to have MBL.

This study was approved by the institutional review boards of Mayo Clinic and Olmsted Medical Center, and participants provided written informed consent. Study participants were from the Mayo Clinic Biobank, a large-scale bio-repository of adult patients recruited through mailed invitation prior to their visit in primary care-based clinics, which ascertains patients' vaccination history regardless of when vaccinations were given [14]. Participants had stored peripheral blood mononuclear cells (PBMC) collected from $7 / 14 / 2009$ to $12 / 31 / 2020$ that were screened for MBL, were residents of Olmsted county (location of Mayo Clinic), Minnesota at the time of sample collection, were 40 years of age or older with no prior history of hematologic malignancy, and had at least five years of medical history in the community prior to screening. For medical abstraction, we utilized the Rochester Epidemiology Project (REP), which is a populationbased medical records-linkage system with access to the complete (in-patient and out-patient) medical records from all medical facilities in Olmsted county [15]. Using the REP, we queried medical records as far back as 1995 for any recorded history of vaccinations (regardless of when vaccination was given). Serious infections were defined as an individual who was hospitalized with an infection. Using the REP, we identified and reviewed all hospitalizations in the five years prior to sample collection for infections, following our published approach [4]. The five-year time period was selected to ensure the same amount of time of medical history. The medical record abstractor collecting data was blinded to MBL status.

Our MBL screening method has been previously published [5]. Briefly, PBMC's were screened using an eight-color flow cytometry assay capable of detecting clonal B-cell events to the $0.005 \%$ level. Individuals with high-count MBL were those who had a percent clonal B-cell count $\geq 85 \%$ out of total B-cell count $[3,16]$.

Logistic regression was used to estimate odds ratios (OR) and $95 \%$ confidence intervals $(\mathrm{Cl})$ to evaluate the association of prior vaccinations and serious infections with $\mathrm{MBL}$ risk (overall and by low-count CLL-like), adjusting for age (continuous) at sample collection, sex, and race/ethnicity. $P$ value was Bonferroni corrected for 30 tests (22 vaccines and 8 infection types) and $P<0.001$ was considered statistically significant. Analyses were performed using SAS ${ }^{\oplus}$ version 9.4 (SAS Institute, Cary, NC, USA) and $\mathrm{R}$ version 3.6.2.

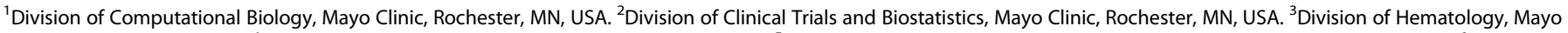

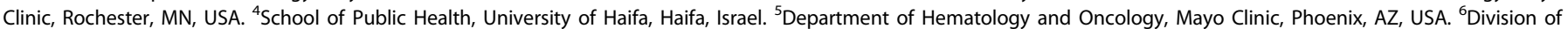

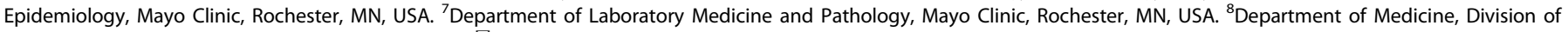
Hematology, Stanford University, Stanford, CA, USA. ${ }^{\bowtie}$ email: Slager.Susan@mayo.edu

Received: 2 July 2021 Revised: 13 January 2022 Accepted: 26 January 2022

Published online: 15 February 2022 
Table 1. Patient characteristics.

\begin{tabular}{|c|c|c|c|}
\hline & $\begin{array}{l}\text { Controls }(N= \\
\text { 4419) }\end{array}$ & $\begin{array}{l}\text { MBL }(N= \\
1009)\end{array}$ & $\begin{array}{l}\text { Total }(N= \\
5428)\end{array}$ \\
\hline $\begin{array}{l}\text { Age years, median } \\
\text { (range) }\end{array}$ & $\begin{array}{l}65.8 \\
(40.2-101.3)\end{array}$ & $\begin{array}{l}73.1 \\
(41.0-97.5)\end{array}$ & $\begin{array}{l}67.3 \\
(40.2-101.3)\end{array}$ \\
\hline \multicolumn{4}{|l|}{ Age group } \\
\hline $40-49$ & $470(10.6 \%)$ & $16(1.6 \%)$ & $486(9.0 \%)$ \\
\hline $50-59$ & $910(20.6 \%)$ & $113(11.2 \%)$ & $1023(18.8 \%)$ \\
\hline $60-69$ & 1352 (30.6\%) & $250(24.8 \%)$ & $1602(29.5 \%)$ \\
\hline 70-79 & $1096(24.8 \%)$ & $373(37.0 \%)$ & $1469(27.1 \%)$ \\
\hline $80+$ & 591 (13.4\%) & $257(25.5 \%)$ & $848(15.6 \%)$ \\
\hline Sex (Male) & 1531 (34.6\%) & $486(48.2 \%)$ & 2017 (37.2\%) \\
\hline \multicolumn{4}{|l|}{ Race/Ethnicity } \\
\hline Non-Hispanic White & 4231 (95.7\%) & $969(96.0 \%)$ & 5200 (95.8\%) \\
\hline Other & $188(4.3 \%)$ & $40(4.0 \%)$ & $228(4.2 \%)$ \\
\hline \multicolumn{4}{|l|}{ MBL immunophenotype } \\
\hline No MBL & 4419 (100.0\%) & - & 4419 (81.4\%) \\
\hline CLL-like MBL & - & 866 (85.8\%) & $866(16.0 \%)$ \\
\hline $\begin{array}{l}\text { Atypical CLL- } \\
\text { like MBL }\end{array}$ & - & $36(3.6 \%)$ & $36(0.7 \%)$ \\
\hline Non-CLL like MBL & - & 107 (10.6\%) & $107(2.0 \%)$ \\
\hline \multicolumn{4}{|l|}{ MBL Sub-classification } \\
\hline Low-count MBL & - & 947 (93.9\%) & - \\
\hline High-count MBL & - & $62(6.1 \%)$ & - \\
\hline
\end{tabular}

MBL monoclonal B-cell lymphocytosis, CLL chronic lymphocytic leukemia.
A total of 5428 individuals were screened for MBL; 1009 (18.6\%) were identified to have MBL and 4419 (81.4\%) did not (controls) (Table 1). Among the MBL individuals, 866 (85.8\%) had a CLL-like MBL subtype, and 947 (93.9\%) were classified as low-count MBL. Individuals with MBL had a median age of 73.1 years compared to 65.8 years in controls $(p<0.001)$.

Prior history of 22 types of vaccines were abstracted from medical records. The frequency of individuals that received the vaccines of interest ranged from $0.1 \%$ (e.g., cholera) to $99.5 \%$ (e.g., tetanus) (Fig. 1A). After adjusting for age at sample collection, sex, and race/ ethnicity, none of the 22 vaccines were statistically significantly associated with $\mathrm{MBL}$ risk (ORs from 0.87 to 1.84) or low-count CLL-like MBL (ORs from 0.85 to 1.97, Supplementary Fig. 1A). Because the extent of medical record coverage varied by individuals, we also performed sensitivity analyses using the same time frame of medical record coverage for all individuals (5 years prior to $\mathrm{MBL}$ screening), and the results were consistent (data not shown). Finally, to account for varying introduction of vaccine immunization schedules, we stratified the cohort by age (younger than 65 years and $65+$ ) and again the results were consistent across age groups (data not shown).

In the five years prior to sample collection, we abstracted eight classifications of infections associated with hospitalizations (Fig. 1B). A total of 257 (5.8\%) controls and 77 (7.6\%) MBL individuals had prior history of serious infection (Fig. 1B and Supplementary Table 1). After adjusting for age at sample collection, sex, and race/ethnicity, there was no association of any infection with risk of MBL (OR= 0.99; $95 \% \mathrm{Cl}$ : $0.75-1.31$ ), or any specific infection (Fig. 1B).

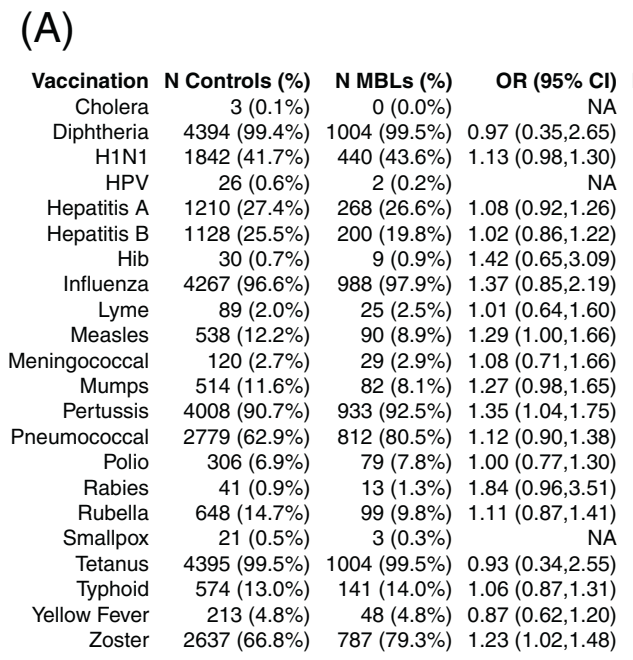

(B)

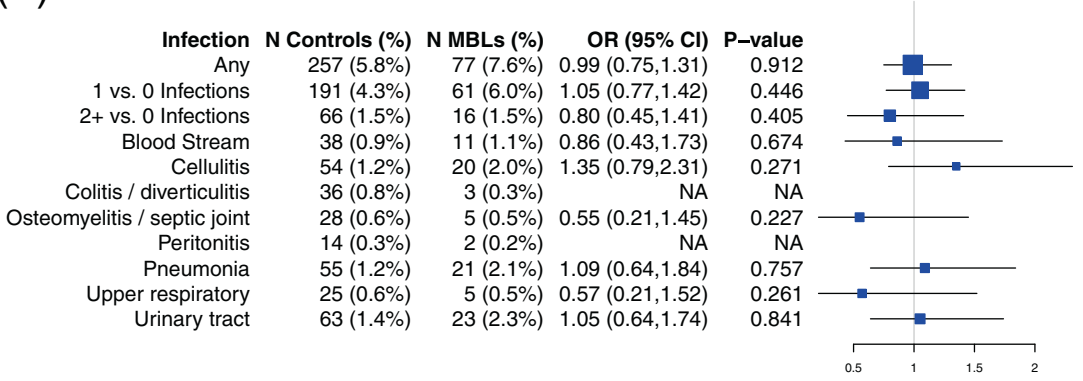

Fig. 1 Prior history of vaccinations and serious infection wtih risk of monoclonal B-cell lymphocytosis (MBL). Association between monoclonal B-cell lymphocytosis (MBL) and history of vaccinations (A) and serious infections (B) prior to MBL screening, adjusting for age at sample collection, sex, and race/ethnicity. Zoster was restricted to individuals aged 50 and older. $\mathrm{N}$ number exposed, OR odds ratio, Cl confidence interval, HPV human papillomavirus, Hib Haemophilus influenzae type B, NA not applicable (too few events $(<5)$ for stable OR calculation). 
Additionally, there was no evidence of an association between the number of serious infections and risk of MBL (Fig. 1B). Similar results were found when we subset to low-count CLL-like MBL (Supplementary Fig. 1B).

This study involving $>5000$ individual ( $1009 \mathrm{MBL}$ and 4419 controls) is the largest study to date to comprehensively investigate history of vaccination and serious infection prior to screening for MBL. We did not find any evidence of an association with either of these two immune agents. Our results conflict with a prior study that investigated history of vaccination and history of infection in 72 individuals with low-count MBL and 380 controls [11]. Specifically, that study reported individuals with low-count MBL were less likely to report having received pneumococcal and influenza vaccination and more likely to report having a history or pneumonia, meningitis, or influenza. These findings could be due to chance or due to the data collected from a self-reported questionnaire, whereas our data were abstracted from medical records.

Studies have documented that individuals with both low-count and high-count MBL are at increased risk of developing a subsequent serious infection, suggesting MBL is a marker of future infection risk $[4,5]$. Individuals with low-count MBL have a 1.6- fold higher risk of hospitalization with infection [5], and individuals with high-count MBL have a 3.0- fold increased risk compared to controls [4]. We have also previously shown that individuals with early stage CLL are at 3.2-fold greater risk for subsequent infection than controls [4]. Based on our current study, prior history of serious infection appears to have no evidence of a role in the initiation of the MBL clone. Collectively, the current literature suggests that the greater the size of the clonal B-cell population, the greater the susceptibility to serious infections rather than infections causing development of the clone.

Moreover, our data may also lend some insight to prior reports of an association between history of infection and risk of CLL $[6,7]$, in that risk of CLL reported in these studies may be due to the CLL patients having preexisting MBL resulting in susceptibility to serious infections rather than history of serious infections resulting in CLL. Additional prospective studies are needed to better understand the relationship and temporality between MBL and infections with risk of CLL.

A limitation of our study is the cross-sectional design for MBL ascertainment which identified prevalent MBL cases, leading to the potential for prevalence-incidence bias and inability to address temporality. Accordingly, we were unable to evaluate the timing of vaccination/serious infection in relationship to MBL onset. Regardless, given the null results, this limitation is unlikely to impact our conclusions. Our definition of low-count or high-count MBL is based on the precent clonal B-cell counts out of the total B-cell counts. Although not the standard definition, this approach was first reported as a reliable way to distinguish high-count MBL from lowcount MBL over a decade ago [16] and we have shown it has high sensitivity (92\%) and specificity (97\%) with the standard definition [3]. Last, we lacked the granularity to investigate risk of MBL based on type of infection (i.e., viral vs. bacterial), and we note that none of the individuals in this study were hospitalized due to Covid-19 infection prior to sample collection.

In summary, we found no evidence of an association of history of vaccinations or serious infections with MBL risk.

\section{REFERENCES}

1. Swerdlow SH, Campo E, Pileri SA, Harris NL, Stein H, Siebert R, et al. The 2016 revision of the World Health Organization classification of lymphoid neoplasms. Blood. 2016;127:2375-90.

2. Landgren O, Albitar M, Ma W, Abbasi F, Hayes RB, Ghia P, et al. B-cell clones as early markers for chronic lymphocytic leukemia. N Engl J Med. 2009;360:659-67.

3. Slager SL, Lanasa MC, Marti GE, Achenbach SJ, Camp NJ, Abbasi F, et al. Natural history of monoclonal B-cell lymphocytosis among relatives in CLL families. Blood. 2021;137:2046-56.
4. Moreira J, Rabe KG, Cerhan JR, Kay NE, Wilson JW, Call TG, et al. Infectious complications among individuals with clinical monoclonal B-cell lymphocytosis (MBL): a cohort study of newly diagnosed cases compared to controls. Leukemia. 2013;27:136-141.

5. Shanafelt TD, Kay NE, Parikh SA, Achenbach SJ, Lesnick CE, Hanson CA, et al. Risk of serious infection among individuals with and without low count monoclonal B-cell lymphocytosis (MBL). Leukemia. 2021;35:239-44.

6. Anderson LA, Landgren $\mathrm{O}$, Engels EA. Common community acquired infections and subsequent risk of chronic lymphocytic leukaemia. $\mathrm{Br} J$ Haematol. 2009;147:444-9.

7. Landgren O, Rapkin JS, Caporaso NE, Mellemkjaer L, Gridley G, Goldin LR, et al. Respiratory tract infections and subsequent risk of chronic lymphocytic leukemia. Blood. 2007;109:2198-201.

8. Chiorazzi N, Ferrarini M. B cell chronic lymphocytic leukemia: lessons learned from studies of the B cell antigen receptor. Annu Rev Immunol. 2003;21:841-894.

9. Stevenson FK, Caligaris-Cappio F. Chronic lymphocytic leukemia: revelations from the B-cell receptor. Blood. 2004;103:4389-95.

10. Ramsay AG, Johnson AJ, Lee AM, Gorgun G, Le Dieu R, Blum W, et al. Chronic lymphocytic leukemia $T$ cells show impaired immunological synapse formation that can be reversed with an immunomodulating drug. J Clin Invest. 2008;118:2427-37.

11. Casabonne D, Almeida J, Nieto WG, Romero A, Fernandez-Navarro P, RodriguezCaballero A, et al. Common infectious agents and monoclonal B-cell lymphocytosis: a cross-sectional epidemiological study among healthy adults. PLoS ONE. 2012;7:e52808.

12. Lankes HA, Fought AJ, Evens AM, Weisenburger DD, Chiu BC. Vaccination history and risk of non-Hodgkin lymphoma: a population-based, case-control study. Cancer Causes Control. 2009;20:517-23.

13. Kleinstern G, Larson MC, Ansell SM, Thompson CA, Nowakowski GS, Call TG, et al. Vaccination History and Risk of Lymphoma and Its Major Subtypes. Cancer Epidemiol Biomarkers Prev. 2022;31:461-70.

14. Olson JE, Ryu E, Hathcock MA, Gupta R, Bublitz JT, Takahashi PY, et al. Characteristics and utilisation of the Mayo Clinic Biobank, a clinic-based prospective collection in the USA: cohort profile. Bmj Open. 2019;9:e032707.

15. St Sauver JL, Grossardt BR, Yawn BP, Melton LJ, Rocca WA. Use of a medical records linkage system to enumerate a dynamic population over time: the rochester epidemiology project. Am J Epidemiol. 2011;173:1059-68.

16. Shanafelt TD, Kay NE, Jenkins G, Call TG, Zent CS, Jelinek DF, et al. B-cell count and survival: differentiating chronic lymphocytic leukemia from monoclonal B-cell lymphocytosis based on clinical outcome. Blood. 2009;113:4188-96.

\section{AUTHOR CONTRIBUTIONS}

Concept and study design was performed by: SLS and NJB. Acquisition of data was performed by: TDS, SAP, CEL, CAH, JEO, ADN and SLS. Analysis of data was performed by: NJB, SJA, KGR and SLS. Interpretation of data was performed by all authors. Manuscript was drafted by NJB and SLS. Manuscript was reviewed by all authors.

\section{FUNDING}

This work was supported by the National Institutes of Health grants R01 AG58266 and R01 CA197120. The Mayo Clinic Center for Individualized Medicine provided the Mayo Clinic Biobank materials.

\section{COMPETING INTERESTS}

The authors declare no competing interests.

\section{ADDITIONAL INFORMATION}

Supplementary information The online version contains supplementary material available at https://doi.org/10.1038/s41375-022-01514-3.

Correspondence and requests for materials should be addressed to Susan L. Slager.

Reprints and permission information is available at http://www.nature.com/ reprints

Publisher's note Springer Nature remains neutral with regard to jurisdictional claims in published maps and institutional affiliations. 
Open Access This article is licensed under a Creative Commons At c) Atribution 4.0 International License, which permits use, sharing,
adaptation, distribution and reproduction in any medium or format, as long as you give appropriate credit to the original author(s) and the source, provide a link to the Creative Commons licence, and indicate if changes were made. The images or other third party material in this article are included in the article's Creative Commons licence, unless indicated otherwise in a credit line to the material. If material is not included in the article's Creative Commons licence and your intended use is not permitted by statutory regulation or exceeds the permitted use, you will need to obtain permission directly from the copyright holder. To view a copy of this licence, visit http://creativecommons. org/licenses/by/4.0/.

(c) The Author(s) 2022 